\title{
RESENHA Tradição, transmissão e emoção religiosa
}

Marcelo Ayres Camurça*

BARRERA RIVERA, Paulo. Tradição, transmissão e emoção religiosa. Sociologia do Protestantismo na América Latina. São Paulo: Olho D’Água, 2001. 299 p.

\section{Introdução}

O livro de Paulo Barrera Rivera é uma obra de fôlego. A rigor, podemos dizer que nele estão contidos dois livros: um, que cumpre de modo formal e rigoroso aquelas exigências de uma Tese de Doutorado, da interlocução exigida com as teorias consagradas no nosso campo acadêmico - quando aborda temas como: racionalidade, tradição e carisma, secularização, desencantamento, modernidade -, e outro, que lança uma agradável aragem de novidade, quando traz à tona a perspectiva da transmissão e do recurso à memória, ausentes (até onde eu acompanho) da sociologia da religião praticada no país.

Acrescente-se que esta perspectiva nova ajuda a lançar luz no complexo terreno da religião contemporânea, marcado pela velocidade de suas transformações, assim como traz novos elementos para pensar as mutações ocorridas no protestantismo latino-americano, com a eclosão do fenômeno pentecostal.

\section{Inovações e interlocuções com temas consagrados da socio- logia da religião}

O que me parece inovador na abordagem do livro sobre o fenômeno religioso é a sua postulação de deslocar-se de uma já tão esquadrinhada sociologia do poder religioso para uma sociologia da transmissão religiosa. Ou seja, o enfoque deixa de estar na gestão, administração e conteúdos das instituições

* É doutor em Antropologia pelo Programa de Pós-Graduação em Antropologia Social (PPGAS) do Museu Nacional da Universidade Federal do Rio de Janeiro (UFRJ) e docente do Programa de Pós-Graduação em Ciência da Religião (PPCIR) da Universidade Federal de Juiz de Fora (UFJF). E-mail: mcamurca@terra.com.br .

** Essa resenha foi originalmente publicada na revista Numen, da Universidade Federal de Juiz de Fora, v. 5, n. 2, jul./dez. 2002. 
religiosas para contemplar a dinâmica do crer na sua reprodução, onde a mobilização da memória do fato fundador funciona como garantia de continuidade da religião. Para tal, ele se inspira na "sociologia da memória", de Maurice Halbwachs. Isto não quer dizer que a reprodução religiosa não esteja ligada à questão do poder; no entanto, segundo Barrera Rivera (2001, p. 54), ela não se restringe ou se resume a essa esfera. Dentro desta visão, a especificidade do fenômeno religioso dá-se pela capacidade de se estabilizar em cima de uma fidelidade às origens e à tradição. Visando garantir sua legitimidade, estabelecese uma "memória autorizada" (HALBWACHS, 1994), a partir, é claro, dos detentores do poder religioso, como versão fidedigna da origem, com fins de ser transmitida e perpetuada. Desta forma, a crença religiosa é sempre uma espécie de lembrança (p. 45). Dentro do enfoque da "transmissão religiosa", a religião estrutura-se sob um "caráter conflituoso", pois as constantes mudanças operadas em seu seio para responder às transformações da sociedade são mascaradas pelo "imperativo de continuidade", que reafirma a fidelidade aos fatos fundadores, o que Halbwachs chamou de "ilusão de não mudança" (p. 78). Nesse sentido, a força das crenças religiosas reside na dinâmica da memória e de sua transmissão como um processo complexo que percebe os fatos originais em estado de preservação mesmo em meio às suas transformações (p. 82).

Ao lado desse interessante enfoque da transmissão e memória religiosa, a argumentação do livro também dedica e consome páginas e capítulos num intrincado e erudito debate sobre as vantagens dos conceitos de "desencantamento" (Weber) e de "saída da religião" (Gauchet), para demonstrar a não incompatibilidade entre religião e modernidade/secularização. Conceitos que, a meu ver, não alcançam tão bem quanto a sociologia da transmissão religiosa (a faceta mais rica de seu argumento) uma interpretação para o "boom" de magia instrumental e da emoção presentes nos pentecostalismos contemporâneos, na contramão da ação devastadora do "desencantamento" e da racionalidade, apresentadas como imperantes na modernidade e colonizadoras das religiões vigentes.

Considero, desta maneira, que, na distribuição dos pesos das argumentações teóricas apresentadas pelo autor, a possibilidade de preeminência da perspectiva inovadora da "sociologia da memória" de Halbwachs - a despeito de a ele ter sido dedicado um capítulo - termina um tanto ofuscada pela avalanche dos temas recorrentes da sociologia da religião arrolados. E nesse particular, à figura de Halbwachs é interposta a de um dos grandes "pais fundadores" da sociologia (da religião), Max Weber, que funciona como uma sombra da obrigatoriedade de presença dos temas sociológicos clássicos no desenvolvimento da perspectiva da sociologia da transmissão religiosa. Esta presença encompassadora aparece tanto como potencialidade, quando 
Barrera Rivera afirma que "o pensamento weberiano oferece bases para uma sociologia da transmissão" (p. 59), quanto como restrição, quando enfatiza "as limitações da teoria weberiana" que não aborda a transmissão e reprodução religiosa e sim seu poder (p. 61).

Ao analisar as transformações ocorridas na cultura contemporânea, que influem diretamente na crença religiosa e sua transmissão - como a destradicionalização, quando as tradições se encontram desvinculadas das culturas e lugares, a serviço dos indivíduos (p. 193) e a desregulação religiosa, perda da capacidade reguladora pelas instituições, o que implica na autonomia do sujeito religioso -, vem à tona a seguinte questão (do ponto de vista da sociologia da transmissão religiosa): se a religião funda-se na tradição, como ela pode persistir na sociedade contemporânea movida por mudanças sucessivas? Ou seja, qual o futuro da tradição religiosa em um quadro de fragilidade da memória religiosa? (p. 82). A análise do autor encaminha-se, então, para contemplar o fenômeno da destradicionalização no sistema de transmissão religiosa, marcado pela passagem da legitimidade da transmissão pela tradição para a legitimidade da transmissão pela emoção (p. 18), que engendra um novo tipo de transmissão religiosa, centrado no emocional.

Neste particular, uma outra autora desponta como referência, na senda da perspectiva de Halbwachs, para a análise do livro: Danièle Hervieu-Léger, que coloca o foco de investigação na compreensão das mutações modernas da memória para sua análise das religiões contemporâneas (p. 208). No entanto, da mesma forma que para Halbwachs, considero que o pensamento de Hervieu-Léger ainda ficou no texto um tanto comprimido entre outros autores utilizados como: Lyotard, Giddens, Baudrillard, etc., que centram suas análises sobre a modernidade (e indiretamente sobre a religião) no campo dos dilemas da racionalidade e da secularização, e não da transmissão e da memória. Apesar disso, o autor, referenciado em Hervieu-Léger, mostra que as sociedades atuais são distintas das "sociedades de memória", por não precisarem de se referenciar no passado para se constituir (p. 208). Nas nossas sociedades, não há mais recurso ao passado para dar sentido ao presente e imaginar o futuro; ao contrário, vive-se um presente exclusivo e contínuo (p. 209). A rapidez das mudanças sociais impõe uma memória imediatista, que substitui a memória como condição de continuidade. A importância sociológica deste fenômeno não está na crise das tradições, mas na crise de sua transmissão (p. 209).

\section{Um novo olhar para a sociologia do protestantismo e pente- costalismo na América Latina}

Para Barrera Rivera, há uma "fragilidade sociológica" no protestantismo, que, se por um lado, garantiu-lhe um lugar de destaque no mundo 
moderno, por sua sintonia com as atitudes de livre-arbítrio e do individualismo, por outro, não lhe assegurou continuidade, pela insuficiência de indicadores palpáveis no seu sistema de transmissão (p. 143). Isto se dá por três aspectos de sua configuração enquanto religião. O primeiro deles se encontra na forma escolhida para a sanção de sua verdade religiosa, que se baseia na referência aos fatos fundadores através da interpretação de um livro sagrado, a Bíblia, o que resulta num pluralismo hermenêutico. Devido ao princípio de "Sola Scriptura", o caráter divino da instituição é questionado, gerando diversas alternativas eclesiásticas (p. 144-145) e a autonomia do fiel em relação às igrejas (p. 153). O segundo deles confere prioridade para o indivíduo diante da instituição, ou seja, o "sacerdócio universal dos fiéis" quebra o monopólio de interpretação do Sagrado pelo clero e age como fator de individualização da experiência religiosa (p. 153). O culto, elemento central do sistema religioso, é relativizado pelas possibilidades individuais de experiência e interpretação da verdade religiosa (p. 154). O acesso à Bíblia por parte dos fiéis leva a uma pluralidade de opiniões que torna o Sagrado objeto de discussão, questionamento e escolha (p. 154). Por fim, o terceiro deles está no caráter ambíguo da figura do sacerdote nesta religião, que se legitima mais pelo saber teológico do que por um status sagrado (p. 146), pois a ênfase da verdade, na crença protestante, está antes na mensagem revelada e na sua hermenêutica do que numa instituição, ritos ou funções portadoras do Sagrado (p. 146). O protestantismo, por não estar calcado no rito, mas no discurso, leva a uma interpretação variada e sujeita ao jogo hermenêutico (p. 149), terminando por desencantar seu culto; pois, ao contrário do rito, que não quer se explicar, o discurso deve mostrar coerência (p. 150). Distinto do rito, que integra, o discurso desintegra, pois leva a diferentes interpretações (p. 150).

Como forma de criar uma eficácia na transmissão e superar sua "fragilidade" neste particular, o "protestantismo recebido" (p. 135-136) na América Latina, segundo Barrera Rivera, desenvolveu, na figura de seus pastores, uma instância de referência e legitimidade, através de sua capacidade de plasmar em si mesmo a verdade religiosa. No protestantismo latino-americano, o prodígio revelado no pastor advém de sua capacidade de levar à conversão, através de um discurso emocional (p. 147). A verdadeira vocação do pastor ficou ligada à experiência do "chamamento" emocional (p. 148). Do ponto de vista da transmissão, o discurso pastoral que promove o êxtase, tem capacidade de integrar porque a emoção elimina as diferenças de interpretação da mensagem transmitida (p. 151). Esta evangelização levada a cabo por hábeis pregadores, propiciando experiências emocionais, distanciou o "protestantismo recebido" do princípio da "Sola Scriptura", com a gradativa perda de importância do texto sagrado nos seus sermões (p. 170) em prol de sua capacidade de des- 
pertar no indivíduo o "encontro com Jesus" através da emoção. Todavia, se o protestantismo latino-americano explorou a emoção no instante da conversão, em seguida abandona este recurso, com o processo de instrução religiosa, estudo bíblico e catequese deste novo convertido, levando a uma rotinização de sua prática religiosa (p. 171). Desta forma, o recém-convertido paulatinamente distancia-se da emoção religiosa fundadora e passa a legitimar sua fé em termos racionais. Através da socialização na nova comunidade religiosa, este neófito passa a construir o perfil de sua nova identidade religiosa em um processo que Barrera Rivera chama "desencantamento da conversão" e "secularização da experiência religiosa” (p. 172).

Penso ser muito acurada a análise do autor quando aponta que, no caso do protestantismo latino-americano, é acrescentado à "clássica" precariedade do protestantismo na transmissão religiosa, a exclusão da emoção pós-conversão, como fator de quebra da eficácia na transmissão. O trabalho de instrução religiosa com a Bíblia foi tão completo que tornou a conversão emocional desnecessária nas próximas gerações advindas dos primeiros convertidos, em prol de um convencimento racional da doutrina e da moral e costumes da religião escolhida (p. 172). No protestantismo latino-americano, após a conversão extática, o cotidiano das práticas religiosas passa a ser orientado pelo seguimento da Bíblia, onde o texto sagrado substitui toda a emoção, trabalhando assim, como no protestantismo clássico (pelos três fatores apontados acima), contra sua reprodução religiosa. Recuperar a tradição (contra a emoção inicial) significou para o protestantismo latino-americano colocar obstáculos à sua reprodução (p. 179).

Numa postura reativa a essa contradição, o pentecostalismo surgido na América Latina introduz uma conversão que não é única, podendo repetir-se tantas vezes quantas a experiência a deflagre. Propicia, ainda, outras experiências religiosas, além desta, onde prevalece a emoção (p. 173). O pentecostalismo está calcado na habilidade de mobilizar a emoção religiosa, e sua eficácia não depende mais da legitimidade tradicional, e sim das respostas às demandas do momento (p. 225). As crenças valem mais pelo seu valor extraordinário que pela sua coerência (p. 233). O evento de Pentecostes se repete sempre como algo novo, não se legitimando pela fidelidade à tradição mas pela força da emoção que carrega (p. 226). No pentecostalismo, a memória fundadora não é reatualizada, a cada culto irrompe um novo fato fundador que apaga e relativiza os anteriores (p. 236). Os ritos não se apoiam na repetição da tradição mas em experiências repetitivas de caráter extraordinário e único (p. 244). Portanto, para o autor, o sucesso do pentecostalismo está relacionado a sua afinidade com a tendência contemporânea da destradicionalização da religião, ou seja, a desvalorização da tradição em todos os campos do mundo atual, inclusive a religião (p. 263). 
Chama atenção na sua análise do pentecostalismo, a interessante etnografia que Barrera Rivera faz da Igreja Pentecostal Deus é Amor (IPDA), embora faça a ressalva que não buscou um estudo de caso (p. 23), pois suas observações da IPDA no Peru, São Paulo e Bahia figuram enquanto particularidades culturais desta igreja transnacional, visando compor a descrição de um "sujeito religioso genérico" (p. 23). As etnografias, para mim, antropólogo de formação, são sempre bem-vindas, pois ajudam a complexificar e relativizar, com vida concreta e cotidiana, muitos esquemas generalizantes. $\mathrm{E}$ no caso dos estudos sobre pentecostalismos, muito se tem escrito de uma forma genérica ou se tem generalizado para todo campo pentecostal, características de um modelo de igreja, como a Igreja Universal do Reino de Deus (IURD). No caso da etnografia de Barrera Rivera sobre a IPDA, seu grau de detalhamento me faz relativizar inclusive a proposição mais geral do autor de que o pentecostalismo latino-americano se afasta da tradição em prol da emoção. Dados como a transubstanciação do pão e do vinho em corpo e sangue de Jesus Cristo, princípios do Catolicismo banidos pela Reforma e praticados pela IPDA nos seus rituais de "Santa Ceia", nos fazem indagar do abandono radical da tradição por parte dessas igrejas. Da mesma forma, a referência recorrente à figura do fundador da igreja, David Miranda e de sua "história sagrada" (p. 254269), o Brasil apresentado como uma "terra santa", uma "Meca" ou "Roma" desta igreja espalhada pela América Latina e outros países (p. 240), os rituais marcados por um espaço exclusivo destinado aos pastores, como um "santo altar" interdito às mulheres e aos diáconos (p. 272), tudo isso são exemplos que emergem de sua etnografia, complexificando seu esquema mais geral.

\section{Conclusão}

Uma resenha é sempre uma nota ao pé da página diante da vastidão de uma obra literária, e esta que se está concluindo não foge à perspectiva. Ela, muitas vezes, funciona como um convite para que o leitor, ele mesmo, faça seu juízo da obra em apreço a partir daquilo (mérito ou polêmica) que chamou atenção do resenhista. Neste sentido, de um lado, considero a obra de Barrera Rivera um exercício teórico exaustivo de pensar a dinâmica do protestantismo/pentecostalismo latino-americano num quadro analítico dos dilemas e perspectivas das abordagens da religião na contemporaneidade. Não obstante, nesta apreciação vão muitas de minhas afinidades e preferências, portanto, acho que, a despeito de sua competente discussão da questão nos marcos das abordagens da secularização/desencantamento, modernidade/ tradição, encontra-se na sociologia da transmissão religiosa de Halbwachs e no recurso à memória a partir da sociologia de Hervieu-Léger, a inspiração mais fecunda, o charme e relevância do seu trabalho, e me arrisco a dizer que será neste aspecto que ele será lembrado. 